\title{
The Effects of Carbonated Water upon Gastric and Cardiac Activities and Fullness in Healthy Young Women
}

\author{
Shiori WAKISAKA ${ }^{1,4}$, Hajime NAGAI ${ }^{2}$, Emi MURA ${ }^{2}$, Takehiro MATSUMOTO ${ }^{3}$, \\ Toshio MORITANI ${ }^{4}$ and Narumi NAGAI ${ }^{1, *}$ \\ ${ }^{1}$ Graduate School of Human Science and Environment, University of Hyogo, 1-1-12 Shinzaike-honcho, \\ Himeji, Hyogo 670-0092, Japan \\ ${ }^{2}$ Frontier Center for Value Creation, Suntory Business Expert Limited, 57 Imaikami-cho, Nakahara-ku, \\ Kawasaki, Kanagawa 211-0067, Japan \\ ${ }^{3}$ Institute for Water Science, Suntory Business Expert Limited, 5-2-5 Yamazaki, Shimamoto-cho, \\ Mishima-gun, Osaka 618-0001, Japan \\ ${ }^{4}$ Graduate School of Human and Environmental Studies, Kyoto University, Sakyo-ku, \\ Kyoto 606-8501, Japan \\ (Received February 27, 2012)
}

\begin{abstract}
Summary Although previous reports suggested that carbonated water drinking was effective against gastrointestinal symptoms, there is little information about the effects of carbonated water on gastric and appetite sensation. We therefore investigated the effect of carbonated water on short-term fullness with respect to gastric and cardiac responses in 19 healthy young women. Each subject was tested on three separate days at approximately 9 a.m. after an overnight fast. Gastric motility, evaluated by electrogastrography (EGG) and heart rate (HR), was measured for $20 \mathrm{~min}$ in the fasting state and $40 \mathrm{~min}$ after ingestion of water. Preloads consisted of an equivalent amount $(250 \mathrm{~mL})$ of water $(W)$ or carbonated water (CW) and no drinking (blank). Fullness scores were measured using visual analog scales. To determine gastric motility, we assessed the component of bradygastria (1-2 cycles/ min $[\mathrm{cpm}])$, normogastria $(2-4 \mathrm{cpm})$, tachygastria $(4-9 \mathrm{cpm})$, and dominant frequency of the EGG power spectrum. After ingestion of CW, significant increases in fullness scores were observed compared with W. All postprandial EGG powers were significantly greater than preprandial, but no group difference was found. However, a dominant frequency tended to shift toward a lower band after ingestion of W. A significantly higher HR was found following consumption of $\mathrm{CW}$ as opposed to W. Multiple regression analysis revealed that increased HR was a significant variable contributing to the variances in fullness after ingestion of $\mathrm{CW}$ at 40 min. Our data suggest that CW may induce a short-term, but significant, satiating effect through enhanced postprandial gastric and cardiac activities due possibly to the increased sympathetic activity and/or withdrawal of parasympathetic activity.
\end{abstract}

Key Words carbonated water, fullness, gastric motility, electrocardiography, heart rate

Carbonated water is plain water or mineral water into which carbon dioxide gas has been added under pressure. In Japan, the consumption of carbonated water has been gradually increased due to a health conscious trend (1). According to previous studies $(2,3)$, carbonated water intake had therapeutic effects including relieving gastrointestinal symptoms such as dyspepsia through improved gastric motility. Since carbonated water is an effervescent beverage, carbonated water brings a perception of gastric fullness through gastric distention (4), which is also associated with gastric motility (5). We recently reported that appetite sensations were positively correlated with the intensity of gastric motility (6) evaluated by electrogastrography (EGG) as shown in other studies $(7,8)$. We therefore hypothesized that carbonated water possesses a satiating effect through enhancement and/or alteration of gastric motility. If this hypothesis is correct, then carbonated

*To whom correspondence should be addressed.

E-mail: nagai@shse.u-hyogo.ac.jp water may useful for prevention of overeating.

The mechanical motility of the stomach is regulated by gastric electrical activity, which consists of rhythmic slow waves (i.e., normal wave) at a frequency of 3 cycles/min (cpm) delivered from pacemaker cells $(5,9)$. Electrogastrography (EGG) has gained popularity with broad applications as a functional indicator of gastric motility because it is an accessible and noninvasive method in which a cutaneous recording of gastric electrical activity is made from surface electrodes placed on the abdomen (9). The parameters calculated from EGG power spectral analysis, such as EGG powers (bradygastria, 1-2 cpm; normogastria, $2-4 \mathrm{cpm}$; tachygastria, 4-9 cpm) and dominant frequency, have been reported to be associated with gastric motility (10-12). In addition, the changes in EGG powers before or after ingestion of water or a meal (13) as well as intra-individual variations are taken to reflect gastric motility. The therapeutic effects of carbonated water on gastric symptoms such as dyspepsia have been well studied (14); however, the satiating effects of carbonated water ingestion and its 
association with EGG parameters are less understood. Interestingly, Chen et al. (5) reported a marked increase in cardiac vagal activity after ingestion of $500 \mathrm{~mL}$ of water; however, such an autonomic response following carbonated water ingestion is not known.

Accordingly, the aim of this study was to determine the effect of carbonated water on short-term appetite sensations (fullness) and its association with gastric motility and cardiac responses in healthy young women.

\section{MATERIALS AND METHODS}

Subjects. We studied 19 healthy young female volunteers (18-24 y) recruited from our university student population. All subjects were non-smokers, free of any symptoms or medical history of gastrointestinal, cardiovascular, or other diseases that could affect gastric motility and appetite, and had a habit of eating breakfast almost every day. The subject characteristics are presented in Table 1. The study protocol was reviewed and approved by the Ethics Committee of the University of Hyogo and was in accordance with the principles of the Declaration of Helsinki. All subjects provided written informed consent.

Experimental procedures. We conducted a randomized cross-over design experiment with three conditions: drinking $250 \mathrm{~mL}$ of water (W), drinking $250 \mathrm{~mL}$ of carbonated water (CW) and no drinking (blank, B). The carbonated water was made by adding carbon dioxide gas to mineral water used for this study. Both water samples were categorized as soft water. Mineral contents and $\mathrm{CO}_{2}$ pressure in representative water samples are presented in Table 2. The temperature of the samples was kept at $15^{\circ} \mathrm{C}$ just before drinking.

Subjects were requested to maintain their usual lifestyle and body weight for at least $1 \mathrm{wk}$ before the test. On the day before the test, the consumption of coffee,

Table 1. Subject characteristics.

\begin{tabular}{lc}
\hline & $n=19$ \\
\hline Age $(\mathrm{y})$ & $19.4 \pm 0.4(18-24)$ \\
Height $(\mathrm{cm})$ & $159.7 \pm 1.4(152.0-171.0)$ \\
Body mass $(\mathrm{kg})$ & $49.9 \pm 1.4(41.3-63.0)$ \\
Body mass index $\left(\mathrm{kg} / \mathrm{m}^{2}\right)$ & $19.7 \pm 0.5(16.1-24.8)$ \\
\% Body fat & $25.3 \pm 0.7(20.6-30.2)$ \\
Systolic blood pressure & $98 \pm 2 \quad(122-77)$ \\
(mmHg) & $65 \pm 2 \quad(84-55)$ \\
Diastolic blood pressure & \\
(mmHg) & $7.2 \pm 0.3(4.1-9.2)$ \\
\hline Energy intake $(\mathrm{MJ} / \mathrm{d})$ &
\end{tabular}

Mean \pm standard error (range). tea, spicy foods, and high-fat foods was prohibited. Dietary intake was estimated from food records with photographs taken using a camera-equipped cellular phone for 2 typical weekdays. These records were carefully checked by registered dieticians through an interview with each subject on the test day. Energy intake and nutritional values were calculated using computer-assisted procedures (Excel Eiyokun ver. 5.5, Kenpakusya Co., Tokyo, Japan) based on the Japanese food consumption table.

Each subject was tested on 3 separate days in a randomized order at approximately 9 a.m. after an overnight fast of at least $10 \mathrm{~h}$. After measurements of body mass and percentage of body fat determined with a bioelectrical impedance analyzer (InBody520, Biospace Co., Soul, Korea), subjects were prepared for an EGG and electrocardiogram (ECG), and then, they rested for at least $15 \mathrm{~min}$ in a sitting-up position on a bed. After the rest period, ECG and EGG were continuously recorded for $20 \mathrm{~min}$ in the preprandial period and $40 \mathrm{~min}$ after ingestion in a sitting-up, $45^{\circ}$ inclined position. Fullness scores were measured 3 times, preprandially ( $-20 \mathrm{~min})$, immediately after ingestion, and 40 min after ingestion, using visual analog scales (15). Water and carbonated water were gradually consumed over a 4 to 5 -min period to avoid immediate belching (4). The room temperature was kept controlled at $25-26^{\circ} \mathrm{C}$, quiet and comfortable, with minimization of arousal stimuli. All subjects were separated by partition screens and requested to maintain their position for the duration of data collection.

EGG measurements and spectral analysis procedures. To derive bipolar EGG signals, 2 active electrodes and 1 ground were positioned on the abdomen according to the American Motility Society Clinical GI Motility Testing Task Force (10). The high-cut frequency of the EGG amplifier was $0.3 \mathrm{~Hz}$, and the low-cut frequency was $0.016 \mathrm{~Hz}$. This band-pass filtering completely eliminated the electrocardiogram (ECG) and $60 \mathrm{~Hz}$ power source artifacts. The EGG signals were amplified (EGG Amplifier BBA-8321, Bio-tex, Kyoto, Japan) and digitized via a 13-bit analog-to-digital converter (DAQ AD135, Elan Digital Systems Ltd, Fareham, UK) at a sampling rate of $0.5 \mathrm{~Hz}$. The acquired data were stored sequentially on a hard disk for later analysis. The root mean square value of the EGG was calculated as representing the average amplitude. After passing through a Hamming-type data window, power spectral analysis was performed with a fast Fourier transformation on a consecutive 512 time series of data obtained during the test. Signal acquisition, storage, and processing were performed on a personal computer. The computer programs for sampling and analysis were written in HTBasic (Trans Era ver 9.0,

Table 2. Mineral contents and $\mathrm{CO}_{2}$ pressure in samples.

\begin{tabular}{lcccccc}
\hline \multicolumn{1}{c}{ Sample } & $\begin{array}{c}\text { Sodium } \\
(\mathrm{mg} / 100 \mathrm{~mL})\end{array}$ & $\begin{array}{c}\text { Calcium } \\
(\mathrm{mg} / 100 \mathrm{~mL})\end{array}$ & $\begin{array}{c}\text { Magnesium } \\
(\mathrm{mg} / 100 \mathrm{~mL})\end{array}$ & $\begin{array}{c}\text { Potassium } \\
(\mathrm{mg} / 100 \mathrm{~mL})\end{array}$ & $\begin{array}{c}\text { Hardness } \\
(\mathrm{mg} / \mathrm{L})\end{array}$ & $\begin{array}{c}\mathrm{CO}_{2} \text {-pressure } \\
\left(\mathrm{kgf} / \mathrm{cm}^{2}\right)\end{array}$ \\
\hline Water & 1.07 & 2.98 & 0.47 & 0.13 & 94 & 0 \\
Carbonated water & 1.07 & 2.98 & 0.47 & 0.13 & 94 & 3.25 \\
\hline
\end{tabular}




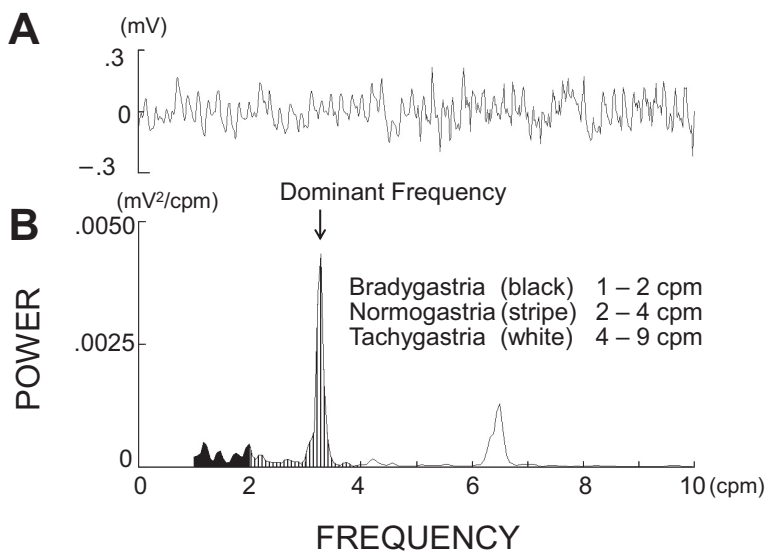

Fig. 1. A typical set of EGG power spectrum analysis results: raw gastric myoelectrical signal (A) and the corresponding power spectrum (B). $\downarrow$ Dominant frequency, a peak of spectrum.

Utah, USA).

To determine the gastric motility, the spectral powers were calculated for the following respective frequency band and corresponding gastric wave: bradygastria (1-2 cpm), normogastria $(2-4 \mathrm{cpm}$, normal wave), tachygastria (4-9 cpm) and dominant frequency of EGG power spectrum $(6,10,16,17)$. A dominant frequency, a peak of the spectrum within the range of $1.0-9.0 \mathrm{cpm}$, was also calculated $(6,10,16,17)$ (Fig. 1).

Fullness questionnaires. Visual analog scales (VAS) $(15,18), 100 \mathrm{~mm}$ in length and anchored at each end, expressing the most positive (extremely) and the most negative rating (not at all), were used to assess fullness sensations. To avoid referring to their previous ratings, the questionnaires were printed as small booklets showing 1 question at a time $(15,18)$.

Statistical analyses. All data are expressed as means \pm standard errors. All analyses were performed using PASW Statistics 19 for Windows (IBM Inc, Tokyo, Japan). Two-way analysis of variance (ANOVA) with repeated measurements was conducted to assess the significant effect of carbonated water (CW) vs. the control trial $(W)$ in fullness, heart rate and EGG parameters. Additionally, an unpaired t-test or Kruskal-Wallis test was used to compare values between $\mathrm{CW}_{\mathrm{CW}-\mathrm{B}}$ and $\mathrm{W}_{\mathrm{W}-\mathrm{B}}$. Significant changes between preprandial (PRE) vs. postprandial (POST) values in each trial (W, CW, and B) were identified by performing Dunnett's test (19). Pearson's correlation analysis was performed to test for associations between fullness score and heart rate. Multiple regression analysis was used to evaluate the impact of $\Delta$ heart rate, bradygastria ratio (POST/PRE), and dominant frequency on fullness scores. The threshold for significance was $p<0.05$.

\section{RESULTS}

\section{Fullness}

Figure 2 shows the time course changes in fullness among the 3 trials (water, carbonated water, and blank). Both water and carbonated water raised postprandial fullness; however, higher fullness scores were observed

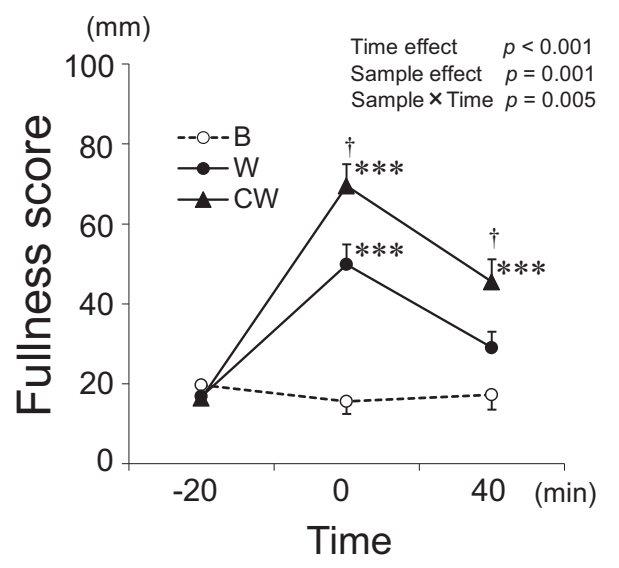

Fig. 2. Changes in the fullness score during preand postprandial periods. The data are expressed as means \pm standard errors. B, blank; W, water; CW, carbonated water. Time effect, sample effect, and sample $\times$ time were calculated by repeated ANOVA, which was performed to assess the effect of the two experiments ( $\mathrm{W}$ and $\mathrm{CW}) .{ }^{\dagger} p<0.05, \mathrm{CW}_{\mathrm{CW}-\mathrm{B}}$ vs. $\mathrm{W}_{\mathrm{W}-\mathrm{B}}$ (Kruskal-Wallis test). ${ }^{* * *} p<0.001$, vs. PRE ( $\left.-20 \mathrm{~min}\right)$ (Dunnett's multiple comparison test).

after ingestion of carbonated water than water (sample effect $p=0.001$, sample $\times$ time $p=0.005$. CW: $p<0.001$, at $40 \mathrm{~min}$, vs. PRE). Focusing on the difference between each ingestion and blank, fullness scores after ingestion of carbonated water $\left(\mathrm{CW}_{\mathrm{CW}-\mathrm{B}}\right)$ were significantly higher compared to the water $\left(\mathrm{W}_{\mathrm{W}-\mathrm{B}}\right)$ at 0 min $\left(\mathrm{CW}_{\mathrm{CW}-\mathrm{B}}\right.$ : $54 \pm 6 \mathrm{~mm}$, vs. $\left.W_{\mathrm{W}-\mathrm{B}}: 34 \pm 6 \mathrm{~mm}, p<0.05\right)$ and $40 \mathrm{~min}$ (CW $\mathrm{CW}_{\mathrm{C}-\mathrm{B}}: 28 \pm 6 \mathrm{~mm}$, vs. $\left.\mathrm{W}_{\mathrm{W}-\mathrm{B}}: 12 \pm 4 \mathrm{~mm}, p<0.05\right)$.

EGG parameters

Figure 3 shows the time course changes in EGG parameters among the 3 trials (water, carbonated water, and blank). After both ingestions, all EGG powers, namely bradygastria, normogastria and tachygastria, were significantly greater compared to before ingestion, but no group difference was found. As to dominant frequency, significant decrease was found for 0-20 min after ingestion of water $(p<0.05)$; by contrast, such a change was not noted after ingestion of carbonated water.

Heart rate

Figure 4 shows time courses of pre- and postprandial heart rate presented at 1 min intervals until 15 min after ingestion. Time courses of heart rate differed among the 2 trials (sample effect $p=0.040$, sample $\times$ time $p<0.001$ ). With regard to carbonated water ingestion, heart rate was transiently but remarkably increased until the first 4 min ( $p<0.001$, until 3 min after; $p<0.05$, until 4 min after, vs. PRE). Conversely, the postprandial values of heart rate were gradually decreased after ingestion of water and remained significantly lower after $15 \mathrm{~min}$ $(p<0.001$, vs. PRE). Focusing on the difference between each ingestion and blank, heart rates after ingestion of carbonated water $\left(\mathrm{CW}_{\mathrm{CW}-\mathrm{B}}\right)$ were significantly higher compared to the water $\left(\mathrm{W}_{\mathrm{W}-\mathrm{B}}\right)$ for the first $5 \mathrm{~min}$, and at 7 min and $13 \min (p<0.05$, respectively).

Correlation analysis and multiple regression analysis

The fullness scores and increase in heart rate were positively correlated at $40 \mathrm{~min}$ after ingestion of car- 

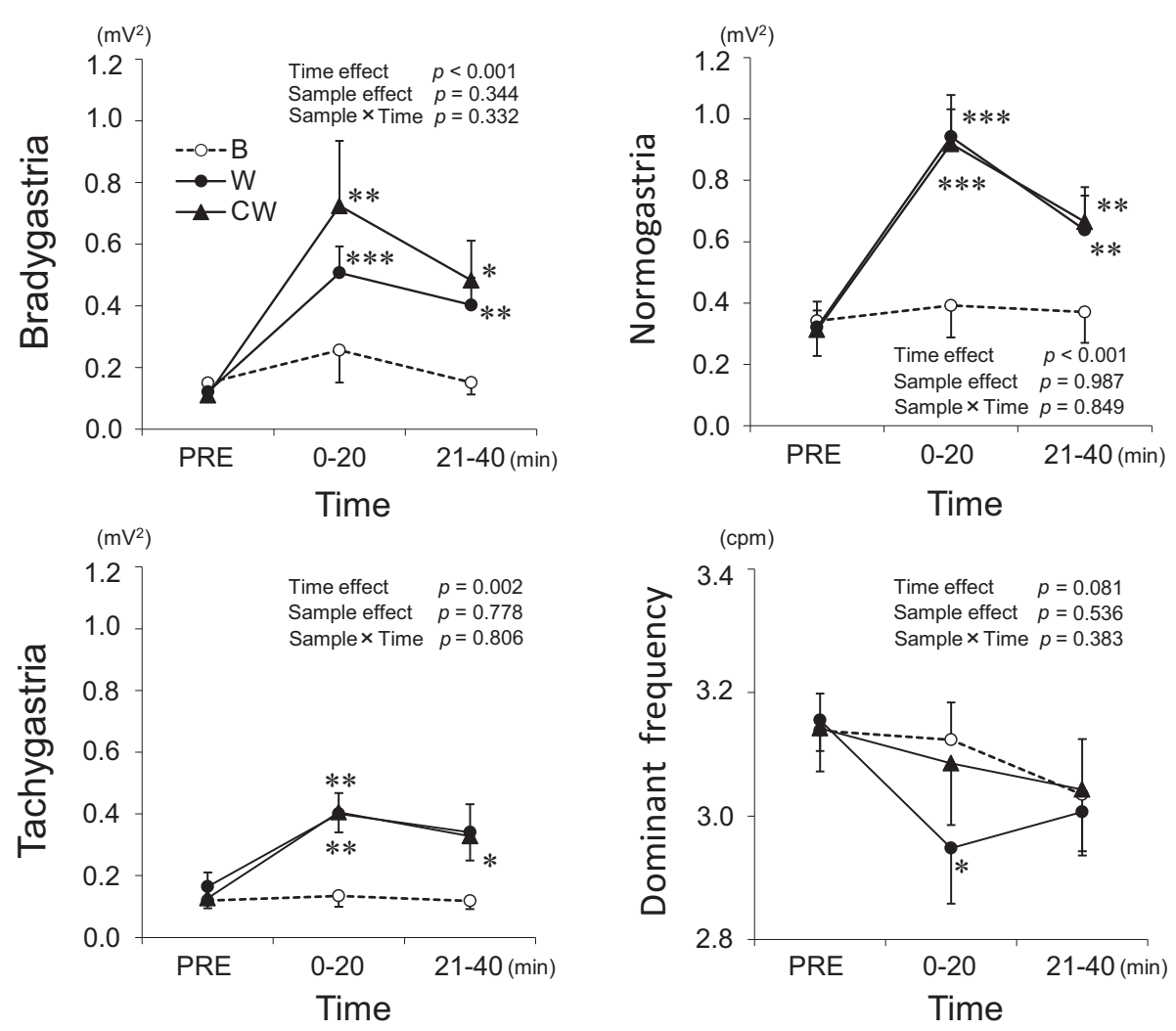

Fig. 3. Changes in the EGG parameters during pre- and postprandial periods. The data are expressed as means \pm standard errors. B, blank; W, water; CW, carbonated water. Time effect, sample effect, and sample $\times$ time were calculated by repeated ANOVA, which was performed to assess the effect of the two experiments (W and CW). ${ }^{* * *} p<0.001,{ }^{* *} p<0.01,{ }^{*} p<0.05$, vs. PRE (-20 min) (Dunnett's multiple comparison test).

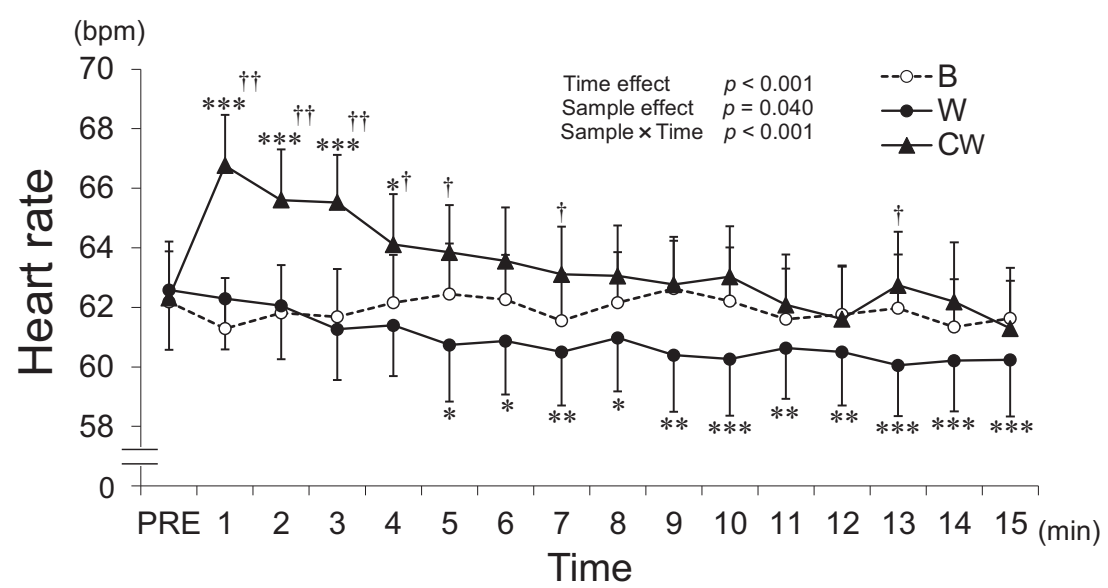

Fig. 4. Magnitude of changes in heart rate during pre- and postprandial periods. The data are expressed as means \pm standard errors. B, blank; W, water; CW, carbonated water. Time effect, sample effect, and sample $\times$ time were calculated by repeated ANOVA, which was performed to assess the effect of the two experiments (W and CW). ${ }^{\dagger} p<0.01,{ }^{\dagger} p<0.05$, CW $\mathrm{CW}-\mathrm{B}$ vs. $\mathrm{W}_{\mathrm{W}-\mathrm{B}}$ (unpaired $t$-test). ${ }^{* * *} p<0.001,{ }^{* *} p<0.01,{ }^{*} p<0.05$, vs. PRE (Dunnett's multiple comparison test).

bonated water $(r=0.516, p=0.024)$. Therefore, we performed multiple regression analysis using the fullness scores as the response variable. As shown in Table 3, a significant, independent and positive correlation was found between changes in heart rate and fullness at 40 min after ingestion of carbonated water $(p<0.05)$. In addition, changes in heart rate tended to show a variance in fullness at $40 \mathrm{~min}$ after ingestion of water $(p=0.055)$. As to EGG parameters, bradygastria ratio and dominant frequency seemed to contribute to the variance in fullness at 40 min after ingestion of carbonated water, but did not reach statistical significance ( $p=0.106, p=0.181$, respectively $)$.

\section{DISCUSSION}

This study showed 3 major findings. First, carbonated water ingestion induced a short-term but significantly greater fullness compared to an equivalent amount of water. Second, similar increases in postprandial EGG powers were observed after ingestion of both water and 
Table 3. Multiple regression analysis with fullness scores as the response variable.

\begin{tabular}{|c|c|c|c|}
\hline Response variable & $\begin{array}{c}\text { Explanatory } \\
\text { variable }\end{array}$ & $\begin{array}{c}\text { Regression } \\
\text { coefficient }\end{array}$ & $p$ value \\
\hline \multicolumn{4}{|l|}{ Water } \\
\hline \multirow[t]{4}{*}{ Fullness at $0 \mathrm{~min}$} & & $R=0.59$ & 0.089 \\
\hline & $\Delta \mathrm{HR}$ & -3.051 & 0.026 \\
\hline & Bradygastria ratio & -0.085 & 0.212 \\
\hline & Dominant frequency & -8.270 & 0.493 \\
\hline \multirow[t]{4}{*}{ Fullness at $40 \mathrm{~min}$} & & $R=0.55$ & 0.142 \\
\hline & $\Delta \mathrm{HR}$ & 2.110 & 0.055 \\
\hline & Bradygastria ratio & -0.257 & 0.730 \\
\hline & Dominant frequency & 7.760 & 0.653 \\
\hline \multicolumn{4}{|l|}{ Carbonated water } \\
\hline \multirow[t]{4}{*}{ Fullness at $0 \mathrm{~min}$} & & $R=0.44$ & 0.345 \\
\hline & $\Delta \mathrm{HR}$ & 2.379 & 0.125 \\
\hline & Bradygastria ratio & 0.029 & 0.537 \\
\hline & Dominant frequency & -4.130 & 0.777 \\
\hline \multirow[t]{4}{*}{ Fullness at $40 \mathrm{~min}$} & & $R=0.64$ & 0.046 \\
\hline & $\Delta \mathrm{HR}$ & 2.706 & 0.045 \\
\hline & Bradygastria ratio & -0.750 & 0.106 \\
\hline & Dominant frequency & -17.521 & 0.181 \\
\hline
\end{tabular}

HR: heart rate. $\Delta$ HR: postprandial HR-preprandial HR. Bradygastria ratio: postprandial bradygastria power/ preprandial bradygastria power.

carbonated water; however, postprandial dominant frequency tended to shift toward a lower band, suggesting slower gastric motility, in the water trial. Third, a significantly higher heart rate was found following consumption of carbonated water as opposed to water ingestion, and increased heart rate was a significant variable contributing to the variances in postprandial fullness.

The classical study of Geliebter et al. (7), where 5 balloons filled with 0 to $800 \mathrm{~mL}$ of water demonstrated that gastric distention itself triggered satiety signals, suggested that the excitation of the gastric stretch receptors transmitted neural signals via the vagal nerve to the hypothalamus. This suggestion was supported by the results of an animal study (20) demonstrating that gastric distention induced activation of a vagal reflex mediated by stretch receptors in the proximal stomach in ferrets. Moreover, a clear association of gastric antral distention and fullness perception has been verified using labeled liquid (21), an ultrasound machine (22) and magnetic resonance imaging (23). In this study, we determined that $900 \mathrm{~mL}$ of gas was released from the $250 \mathrm{~mL}$ of carbonated water by a gas pressure measurement instrument. Accordingly, we suggest that shortterm but the greater fullness perception after ingestion of carbonated water was related to gastric distention due to liberation of dissolved gas because carbon dioxide was the only different component between the 2 water samples.

In light of the fullness and gastric motility (electrical responses), we failed to find a relationship between carbonated water drinking and gastric motility in spite of greater distention of the stomach. A possible reason was that statistical power was not sufficient due to the small sample size. Interestingly, after water ingestion, even a glass of water, the peak frequency of EGG power tended to shift toward a lower band, indicating slower gastric motility as shown in our previous study (17). In contrast, frequency shift was not noted after ingestion of carbonated water despite an increase in all EGG powers. Further studies are needed to clarify these phenomena after carbonated water drinking using larger samples.

The remaining question we must address is why the heart rate increases after ingestion of carbonated water, whereas it decreases after ingestion of water. It is well known that drinking water induces sympathetic vasoconstrictor activation, but this is not accompanied by an increase in arterial blood pressure in healthy young subjects (24). Relevant to this point, Routledge et al. (25) demonstrated that water ingestion in normal subjects caused bradycardia due to an increase in cardiac vagal activity, which may counteract the pressor effects of sympathetic activation. Moreover, this pressor response to modulate blood pressure was not observed in the elderly, in transplant recipients or in autonomic failure patients, providing direct evidence for the explanation of the pressor and autonomic responses to drinking water (25). Consistent with those previous reports, we found decreased heart rates after ingestion of water as a result of normal pressor responses. Regarding carbonated water, we found that increases in heart rate shortly after ingestion may be related to the transient sympathetic acceleration via the oral gustatory receptor to acid taste, which also could be involved in a pain-transmission pathway. These stimulations induced by carbonated water may be stronger at triggering sympathetic activation than those induced by tasteless water.

Regarding the association between heart rate and fullness at $40 \mathrm{~min}$ after ingestion of carbonated water, $\Delta$ heart rate was a significant variable contributing to the variances in fullness. It has been reported that meal ingestion can increase postprandial heart rate (26). Harthoorn and Dransfield (27) also demonstrated that both fullness and heart rate increased after lunch, and found that postprandial fullness was positively correlated with heart rate, and sympatho-vagal balance (sympathetic predominance). Since the sympathetic nervous system has been thought to contribute to the modulation of energy homeostasis and appetite control (28), we did not assess autonomic nerve activity in this study; however, the increased heart rate even after 40 min could reflect maintained sympathetic predominance and/or parasympathetic withdrawal.

This study has three limitations. First, there is gender limitation. Second, the signals recorded with EGG correlated to some degree with gastric emptying and hence with gastric motility, but these signals may be not clearly correlated to actual gastric motility; therefore, the data should be interpreted carefully. Third, since fullness after ingestion disappeared in a short time, further study is needed; this should determine the consumption of a meal after drinking, to confirm the present results. 
In summary, the carbonated water induced a significant increase in postprandial fullness, together with elevated heart rate after $40 \mathrm{~min}$. Our results suggest that carbonated water may induce a short-term, but significant, satiating effect by enhanced postprandial gastric and cardiac activities due possibly to the increased sympathetic activity and/or withdrawal of parasympathetic activity.

\section{Acknowledgments}

We are grateful to all subjects for their cooperation.

This research was supported in part by a Grant-inAid for Scientific Research from the Ministry of Education, Culture, Sports, Science and Technology of Japan (\#21500786).

\section{REFERENCES}

1) 2010 Handbook of Food Marketing Project Team, Tokyo Marketing Division, Fuji-keizai. 2010. Handbook of Food Marketing in Japan 2010, No. 6, p 257-262. Fujikeizai, Tokyo.

2) Gasbarrini G, Miglio F, Arienti V, Biondi S. 1985. Considerations on the therapeutic efficacy of a standard alkaline bicarbonated mineral water in cases of dyspepsia. Minerva Dietol Gastroenterol 31: 55-62.

3) Bortolotti M, Turba E, Mari C, Lopilato C, Porrazzo G, Scalabrino A, Miglioli M. 1999. Changes caused by mineral water on gastrointestinal motility in patients with chronic idiopathic dyspepsia. Minerva Med 90: 187-194.

4) Pouderoux P, Friedman N, Shirazi P, Ringelstein JG, Keshavarzian A. 1997. Effect of carbonated water on gastric emptying and intragastric meal distribution. Dig Dis Sci 42: 34-39.

5) Chen CL, Lin HH, Orr WC, Yang CC, Kuo TB. 2004. Transfer function analysis of heart rate variability in response to water intake: correlation with gastric myoelectrical activity. J Appl Physiol 96: 2226-2230.

6) Wakisaka S, Kobashi R, Hishikawa M, Yamamoto Y, Ikeda M, Sakane N, Matsunaga T, Moritani T, Nagai N. 2009. Association between skipping breakfast and morning gastric motility monitored by electrogastrography. Nippon Eiyo Shokuryo Gakkai Shi (J Jpn Soc Nutr Food Sci) 62: 297-304 (in Japanese).

7) Geliebter A, Westreich S, Gage D. 1988. Gastric distention by balloon and test-meal intake in obese and lean subjects. Am J Clin Nutr 48: 592-594.

8) Wang GJ, Tomasi D, Backus W, Wang R, Telang F, Geliebter A, Korner J, Bauman A, Fowler JS, Thanos PK, Volkow ND. 2008. Gastric distention activates satiety circuitry in the human brain. NeuroImage 39: 1824-1831.

9) Verhagen MA, Van Schelven LJ, Samsom M, Smout AJ. 1999. Pitfalls in the analysis of electrogastrographic recordings. Gastroenterology 117: 453-460.

10) Parkman HP, Hasler WL, Barnett JL, Eaker EY. 2003. Electrogastrography: a document prepared by the gastric section of the American Motility Society Clinical GI Motility Testing Task Force. Neurogastroenterol Motil 15 : 89-102.

11) Yin J, Levanon D, Chen JD. 2004. Inhibitory effects of stress on postprandial gastric myoelectrical activity and vagal tone in healthy subjects. Neurogastroenterol Motil 16: $737-744$.

12) Friesen CA, Lin Z, Schurman JV, Andre L, McCallum RW.
2006. An evaluation of adult electrogastrography criteria in healthy children. Dig Dis Sci 51: 1824-1828.

13) Chen J, McCallum RW. 1991. Response of the electric activity in the human stomach to water and a solid meal. Med Biol Eng Comput 29: 351-357.

14) Cuomo R, Grasso R, Sarnelli G, Capuano G, Nicolai E, Nardone G, Pomponi D, Budillon G, Ierardi E. 2002. Effects of carbonated water on functional dyspepsia and constipation. Eur J Gastroenterol Hepatol 14: 991-999.

15) Flint A, Raben A, Blundell JE, Astrup A. 2000. Reproducibility, power and validity of visual analogue scales in assessment of appetite sensations in single test meal studies. Int J Obes Relat Metab Disord 24: 38-48.

16) Nagai N, Wakisaka S, Takagi A, Yamaguchi M, Moritani T. 2012. Effect of spice-containing soup on gastric motility and appetite sensations. Eiyogaku Zasshi (Jpn J Nutr Diet) 70: 17-27 (in Japanese).

17) Wakisaka S, Matsumoto T, Nagai H, Mura E, Moritani T, Nagai N. 2011. Effects of drink temperature and volume of water ingestion on gastric myoelectrical activity in humans. Nippon Eiyo Shokuryo Gakkai Shi (J Jpn Soc Nutr Food Sci) 64: 19-25 (in Japanese).

18) Nagai N, Hibi M, Yamaguchi T, Kameo Y, Kobayashi S, Katashima M. 2012. Development of the Japanese version of appetite sensations questionnaire using visual analogue scales (VAS), and assessment of its reproducibility and validity. Jpn Soc Study Obes 18: 39-51 (in Japanese).

19) Shaffer JP. 1977. Multiple comparisons emphasizing selected contrasts: an extension and generalization of Dunnett's procedure. Biometrics 33: 293-303.

20) Andrews PL, Grundy D, Scratcherd T. 1980. Vagal afferent discharge from mechanoreceptors in different regions of the ferret stomach. J Physiol 298: 513-524.

21) Jones KL, Doran SM, Hveem K, Bartholomeusz FD, Morley JE, Sun WM, Chatterton BE, Horowitz M. 1997. Relation between postprandial satiation and antral area in normal subjects. Am J Clin Nutr 66: 127-132.

22) Sturm K, Parker B, Wishart J, Feinle-Bisset C, Jones KL, Chapman I, Horowitz M. 2004. Energy intake and appetite are related to antral area in healthy young and older subjects. Am J Clin Nutr 80: 656-667.

23) Marciani L, Gowland PA, Spiller RC, Manoj P, Moore RJ, Young P, Fillery-Travis AJ. 2001. Effect of meal viscosity and nutrients on satiety, intragastric dilution, and emptying assessed by MRI. Am J Physiol Gastrointest Liver Physiol 280: G1227-G1233.

24) Jordan J. 2005. Effect of water drinking on sympathetic nervous activity and blood pressure. Curr Hypertens Rep 7: 17-20.

25) Routledge HC, Chowdhary S, Coote JH, Townend JN. 2002. Cardiac vagal response to water ingestion in normal human subjects. Clin Sci (Lond) 103: 157-162.

26) Fagan TC, Sawyer PR, Gourley LA, Lee JT, Gaffney TE. 1986. Postprandial alterations in hemodynamics and blood pressure in normal subjects. Am J Cardiol 58: 636-641.

27) Harthoorn LF, Dransfield E. 2008. Periprandial changes of the sympathetic-parasympathetic balance related to perceived satiety in humans. Eur J Appl Physiol 102: 601-608.

28) Bray GA. 2000. Reciprocal relation of food intake and sympathetic activity: experimental observations and clinical implications. Int J Obes Relat Metab Disord 24: S8-S17. 